\begin{tabular}{|l|l|}
\hline \multicolumn{2}{|l|}{ TECNOLOGIA } \\
\hline RE & RENATO CRUZ \\
\hline
\end{tabular}

\title{
A HORA DA INTERNET RÁPIDA?
}

\section{Lenta, cara e escassa, a banda larga brasileira está entre as piores do mundo. O Plano Nacional de Banda Larga acena com melhoras, mas apresenta grandes fragilidades}

\footnotetext{
larga estâ presente apenas nas regiões de maior renda e maior densidade populacional. O mercado é dominado por poucas empresas, as tarifas são altas e a qualidade do serviço é baixa pelos padrões internacionais.

No primeiro semestre deste ano, o governo federal instituiu o Plano Nacional de Banda Larga (PNBL) com o objetivo de triplicar o acesso, levando o serviço a localidades ainda não atendidas e a camadas populacionais de menor renda. No entanto, o conjunto de medidas anunciado está distante de configurar uma solução efetiva.
}

QUADRO ATUAL. A banda larga brasileira tem crescido de forma sensível nos últimos anos. Tomando por base os dados do Barômetro Cisco de Banda Larga, estudo realizado pela consultoria IDC Brasil (ver gráfico 1), o número de conexões se expandiu em cerca de 32\% no ano de 2009, e já acumula um crescimento de quase $4.000 \%$ desde 2001.

Tal crescimento, contudo, está longe de corresponder às necessidades da população brasileira. Segundo a última pesquisa sobre o uso das TICs no Brasil - TIC Domicílios 2009 - divulgada no último mês de abril pelo Comitê Gestor da Internet no Brasil, apenas 27\% dos domicílios brasileiros possuem acesso à internet e, desses, aproximadamente um terço não possui banda larga.

Além de a banda larga brasileira atender a uma parcela ainda restrita da população, a sua velocidade deixa a desejar. Um ranking a esse respeito, divulgado no final do ano passado e realizado pelas universidades de Oxford, da Inglaterra, e Oviedo, da Espanha, colocou a internet rápida do Brasil na 45ª posição, entre as de 66 países analisados. Em 2008, o Brasil ficara em $38^{\circ}$ lugar, entre 42 países contemplados pela pesquisa. 


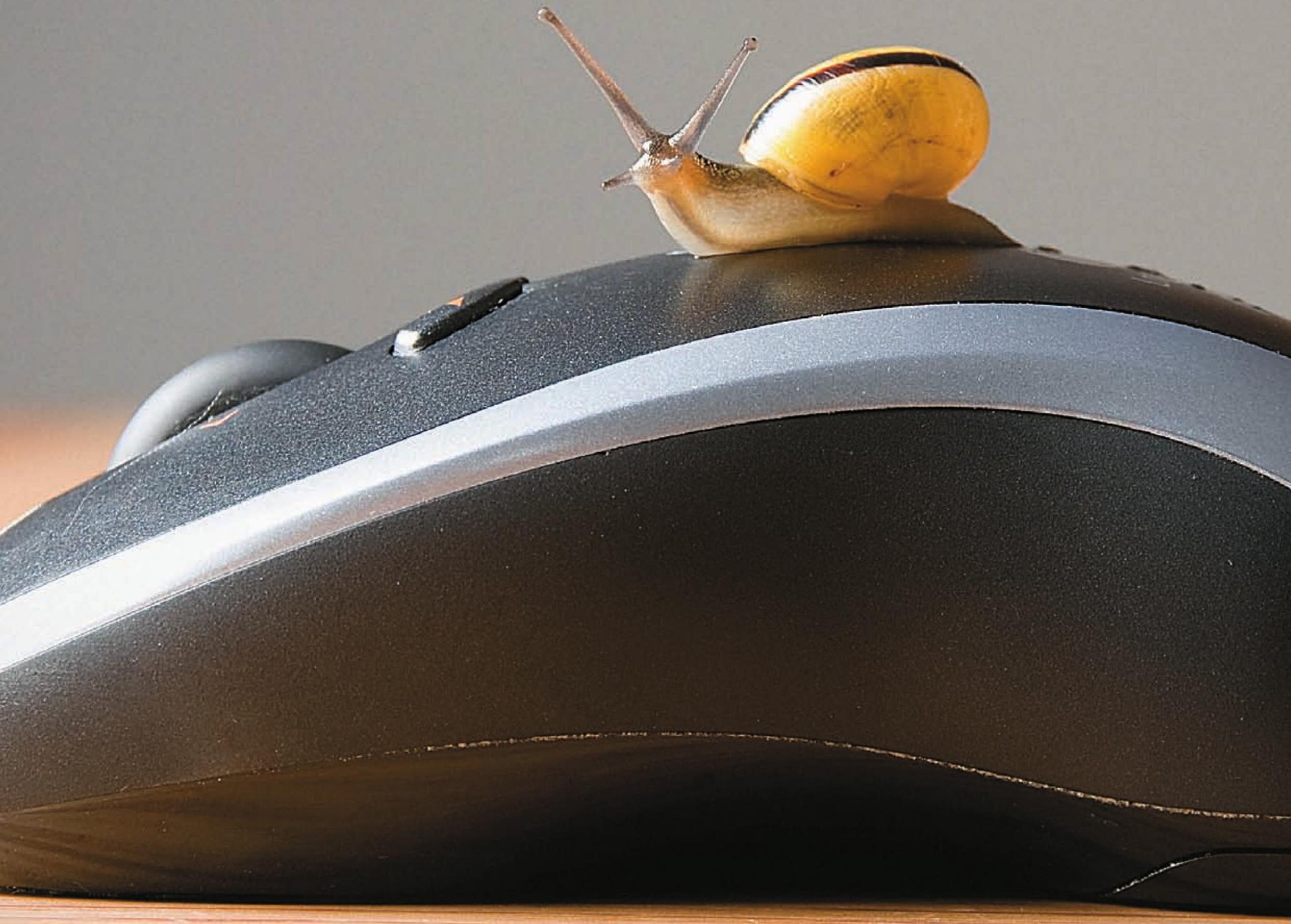


E também existe o problema do custo. Os serviços de telecomunicações no Brasil, aí incluído o acesso à internet, estão entre os mais caros do mundo. Segundo pesquisa recente da União Internacional de Telecomunicações (UIT), o brasileiro gasta em média 4,1\% de sua renda para pagar por tecnologias de comunicação - cerca de dez vezes mais do que nos Estados Unidos ou no Canadá, por exemplo.

PLANO NACIONAL. Para resolver essa situação, foi instituído em maio deste ano, por decreto presidencial, o Plano Nacional de Banda Larga (PNBL). O plano parte do diagnóstico, sem dúvida correto, de que a banda larga brasileira é cara, lenta e escassa. Contudo, as medidas anunciadas estão longe de configurar uma solução adequada para o problema.

O eixo básico das medidas é a reativação da Telebrás, empresa estatal que se encontrava inativa desde a privatização do sistema de telecomunicações brasileiro, em 1998. Na época, o Sistema Telebrás foi fatiado em 12 operadoras e vendido à iniciativa privada. Restou a holding que dava nome ao sistema, e que, apesar da previsão de ser extinta, não o foi por duas razões principais. Em primeiro lugar, ela cedera funcionários à recém-criada Agência Nacional de Telecomunicações (Anatel), enquanto esta não fazia o seu primeiro concurso de contratação; em segundo, a empresa contava - e ainda conta - com um grande passivo judicial, formado principalmente por ações trabalhistas. Desde então, a Telebrás continuou a ter uma existência meramente jurídica, como uma holding sem controladas, uma empresa sem atividade e sem faturamento, que administrava disputas judiciais. O decreto presidencial que instituiu o PNBL tirou-a do limbo, recriando-a como operadora e gestora de redes de fibra óptica do governo.

Ao fazer isso, o PNBL é passível de críticas de pelo menos duas ordens. De um lado, dá respostas pouco efetivas às reais necessidades do mercado. De outro, contradiz o modelo de governança do setor de telecomunicações brasileiro, baseado desde 1998 no Estado regulador e na iniciativa privada.

\section{GRÁFICO 1 - BANDA LARGA BRASILEIRA \\ (em milhões de conexões)}

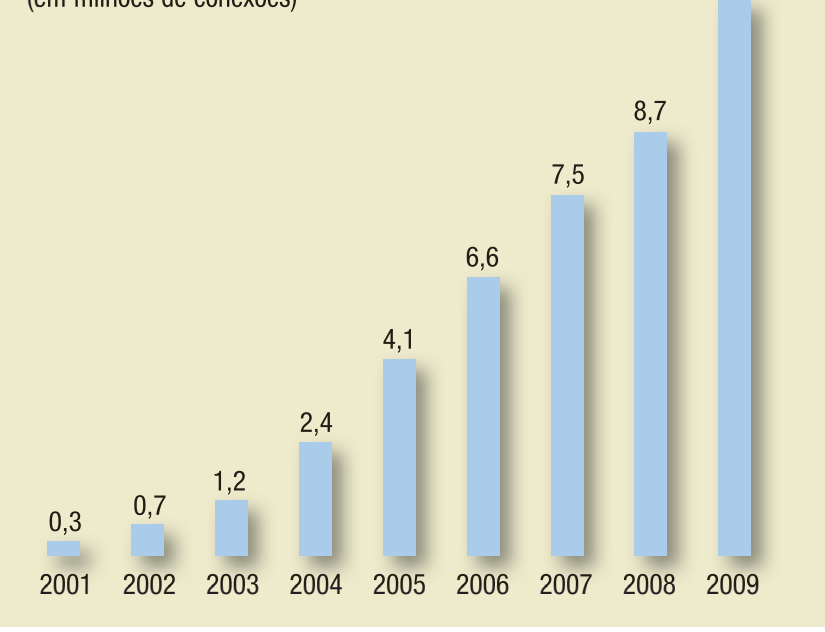

FONTE: BARÔMETRO CISCO DE BANDA LARGA 2010

CAPILARIDADE. Um dos grandes gargalos para o crescimento da banda larga no Brasil é a chamada "última milha", segmento de rede que chega à casa do consumidor. Trata-se da infraestrutura mais cara de se instalar, e, na maioria das regiões, a única opção para tanto são as redes das concessionárias de telefonia locais.

A rede a ser montada pela Telebrás é um backbone (espinha dorsal), que chega até as cidades, mas que não tem capilaridade dentro delas. Existem hoje quatro redes desse tipo no Brasil: a da Embratel, a da Intelig, a da Oi e, em menor escala, a da GVT. O PNBL e a volta da Telebrás, embora permitam a criação de um novo backbone, não resolverão, por si sós, o problema da escassa capilaridade da banda larga.

Medidas efetivas de ampliação da capilaridade poderiam envolver a venda de mais licenças de TV a cabo (principal competidora da internet rápida das concessionárias) e de frequências para a oferta de banda larga sem fio. Existem somente 258 municípios no Brasil com operações de TV a cabo, de um total de 5,5 mil. O PNBL determina que a Anatel retome a venda dessas últimas licenças, suspensa desde 2006, mas não define prazos nem metas para tanto, tampouco para a ampliação da base de assinantes de banda larga. 




PLANOS DE BANDA LARGA: EXPERIÊNCIA INTERNACIONAL

Por Manuella Maia Ribeiro, mestranda da FGV-EAESP

Diversos outros países têm criado planos nacionais para universalizar o acesso à banda larga. A seguir destacamos três experiências, descrevendo os principais pressupostos e as principais metas de cada plano.

FINLÂNDIA. Em 2009, este foi o primeiro país do mundo a decretar o acesso à banda larga como um direito básico do cidadão. O plano, implementado pelo Ministério de Transportes e Comunicações, estabeleceu julho de 2010 como prazo para que todos os cidadãos do país - e também as empresas - disponham de acesso à internet com no mínimo 1 Mbps. Para 2015, o plano tem como meta expandir essa velocidade para um mínimo de 100 Mbps. O plano finlandês de banda larga parte da filosofia de que o bom acesso às telecomunicações, tanto para o trabalho quanto para o lazer, é uma necessidade e não um luxo. Ao mesmo tempo, o plano pressupõe que as empresas privadas de telecomunicações não atenderão a todas as necessidades dos cidadãos, o que demanda a ação do poder público para garantir o acesso igualitário. Um fundo público será criado para subsidiar essas empresas, entre outras ações.

ESTADOS UNIDOS. O plano americano foi lançado em março de 2010, encomendado pelo Congresso à Comissão Federal de Comunicações. Sua proposta é garantir que todos os cidadãos americanos tenham não só acesso à infraestrutura de banda larga, mas também capacidade de usá-la. Segundo o plano, a banda larga se tornou a infraestrutura-chave do século XXI, papel que já foi, no passado, da eletricidade.
Uma característica do plano americano é a participação da sociedade na sua elaboração, por meio de audiências públicas. Diversas metas foram definidas para 2020, entre as quais: a) prover acesso residencial a 100 milhões de famílias a preços acessíveis; b) ser líder em inovação nas tecnologias móveis e ter a mais ampla rede de comunicações sem fio de qualquer nação; d) garantir acesso à banda larga para governos em todos os níveis, com velocidade de pelo menos $1 \mathrm{Gbps}$ para instituições como escolas, hospitais, órgãos públicos etc.

COREIA DO SUL. Desde 1996, cinco planos nacionais já foram implementados para garantir o acesso à infraestrutura de internet na Coreia do Sul. Os sulcoreanos já entraram no rol de países com alta penetração de banda larga, e a universalização não é mais a principal questão. O plano atual, implementado em 2006, tem por objetivo tornar a Coreia do Sul a primeira U-sociedade do mundo, conceito que se caracteriza pela onipresença da tecnologia na sociedade. Trata-se de garantir que, além de ser universal, o acesso à internet de alta velocidade seja ubíquo, isto é, possa ser feito de qualquer lugar e a qualquer momento.

O plano sul-coreano prevê que, até 2015, o país esteja entre os dez mais competitivos do mundo, com acesso geral à banda larga de 1 Gbps. 
REGULAÇÃO. A reativação da Telebrás também conflita com o modelo de regulação do setor de telecomunicações no Brasil, em prática desde 1998. Instituído pela Lei Geral de Telecomunicações (9.472/97), o modelo excluiu a atuação de estatais como fornecedoras de serviços, baseando o funcionamento do setor na atuação de empresas concessionárias privadas, sujeitas à fiscalização de um agente regulador criado para tal fim, a Anatel. Um modelo, por sinal, que não está presente apenas nas telecomunicações, mas de forma geral nos setores fornecedores de serviços públicos. A reinstituição de uma empresa estatal no setor, feita sem consulta à Anatel, órgão teoricamente responsável pela regulação das telecomunicações do país, desestrutura a filosofia que vinha sendo imprimida ao setor na última década, desde o processo de privatização.

Além disso, o decreto que instituiu o PNBL vem sendo apontado como ilegal por especialistas como Floriano de Azevedo Marques, professor da USP, e Carlos Ari Sundfeld, professor da FGV, ambos membros da equipe que elaborou o marco regulatório do setor, em 1997

Um dos principais questionamentos se baseia no fato de que o decreto altera o objetivo social da Telebrás. A lei federal que criou a estatal, em 1972, definiu como objeto social da empresa "gerir a participação acionária do governo federal nas empresas de serviços públicos de telecomunicações do país". O recente decreto, por sua vez, transforma a empresa em operadora, definindo como suas atribuições, entre outras, "prover infraestrutura e redes de suporte a serviços de telecomunicações prestados por empresas privadas, estados, Distrito Federal, municípios e entidades sem fins lucrativos" e "prestar serviço de conexão à internet em banda larga para usuários finais, apenas e tão somente em localidades onde inexista oferta adequada daqueles serviços". Como apontaram os juristas, um decreto não pode mudar o que foi definido em lei, daí sua ilegalidade.

Outro alvo de críticas é o fato de o governo ter anunciado que contratará a Telebrás sem licitação, uma vez que ela foi criada antes da Lei das Licitações (8.666/93) e não estaria, portanto, submetida a ela. Para Marques, isso não é possível porque, embora tenha sido criada antes da Lei 8.666, ela foi criada com outros fins. Sundfeld também aponta conflitos com a Lei Geral de Telecomunicações, que limitou a atuação da Telebrás às seguintes atividades: "Cisão, fusão e incorporação; dissolução de sociedade ou desativação parcial de seus empreendimentos; e redução de capital social".

DESAFIOS. A expansão da banda larga é sem dúvida um dos temas mais importantes e estratégicos para o desenvolvimento econômico e social do país. Permitirá incrementar a inclusão econômica e a cidadania, interiorizar o desenvolvimento e conferir à população e às empresas brasileiras acesso à principal plataforma de comunicação do século XXI. Por isso mesmo, sua discussão deveria ser conduzida de outra forma. Como visto, o PNBL, da forma como foi apresentado, é passível de questionamentos com relação tanto à sua eficácia como também a aspectos jurídicos. Ele pode ainda ser alvo de críticas por conflitar com um modelo de regulação vigente no setor de telecomunicações desde os anos 1990, e que incorpora mais de uma década de esforços de modernização do Estado brasileiro.

Para finalizar, convém lembrarmos que outros países, a exemplo dos Estados Unidos, também anunciaram recentemente planos de expansão da banda larga. Nos Estados Unidos o plano foi elaborado pela agência reguladora, a Federal Communications Commission (FCC), e enviado à discussão no Congresso. No Brasil, os autores foram técnicos do governo que trabalharam a portas fechadas, sem participação da Anatel, e criaram um plano instituído por decreto. Ao contrário do que ocorreu aqui, o plano americano foi resultado de ampla discussão, envolvendo governo e sociedade.

RENATO CRUZ,

jornalista, renatocruz1@gmail.com 